\title{
A liberdade em obras do jovem Marx: referências para reflexões sobre ética
}

\author{
Olegna de Souza Guedes \\ Universidade Estadual de Londrina (UEL)
}

\section{A liberdade em obras do jovem Marx: referências para reflexões sobre ética}

Resumo: Este artigo, elaborado através de revisão bibliográfica, apresenta uma análise da categoria liberdade nos escritos de Karl Marx, no período de 1841 a 1844. Situa a necessidade da análise da liberdade para a reflexão ética e mostra a importância da crítica marxiana para desconstrução de um ideário liberal que a vincula à propriedade privada e à defesa de interesses individuais. Ao evidenciar esse aspecto, remonta à vinculação entre liberdade e trabalho não alienado, o que remete ao horizonte uma nova sociabilidade. Reflete sobre a necessária reposição dessa perspectiva crítica para a interpretação do primeiro princípio do código de ética profissional dos assistentes sociais, no sentido de afirmar os propósitos do projeto ético-político do Serviço Social no Brasil.

Palavras-chave: Liberdade. Ética. Propriedade privada.

\section{Liberty in Works by the Young Marx: References for Reflections on Ethics}

Abstract: This article conducted a bibliographic review to present an analysis of the category of liberty in the writings of Karl Marx, from 1841-1844. It situates the need for an analysis of liberty to conduct an ethical reflection and shows the importance of Marxian criticism for the deconstruction of a liberal ideal that links private property to a defense of individual interests. By revealing this factor, it looks at the tie between liberty and non-alienated work, which refers to the horizon of a new sociability. The paper reflects on the need for a repositioning of this critical perspective for the interpretation of the first principle of the professional code of ethics of social worker, to affirm the proposals of the ethical-political project of Social Work in Brazil.

Key words: Liberty. Ethics. Private property. 


\section{Introdução}

Análises teóricas sobre o projeto ético-político do Serviço Social na contemporaneidade remetem-se, necessariamente, aos princípios do atual código de ética profissional dos assistentes sociais, sancionado no ano de $1993^{1}$. E, dentre esses princípios, destacam-se: "a liberdade e as demandas políticas a ela inerentes - autonomia, emancipação, e plena expansão dos indivíduos sociais" (CFESS, 1993). A necessária interpretação do sentido crítico que esse princípio impõe à categoria profissional dos assistentes sociais motivou a pesquisa que deu origem a este artigo.

Considera-se, previamente, a categoria liberdade como central na reflexão sobre a ética na cultura ocidental, sobretudo a partir do século 18. Período que expressa a necessidade histórica de associá-la com o ideário de um novo tempo, que tem entre seus traços: o individualismo burguês; as possibilidades de conquistas fundadas na racionalidade e no trabalho; a propriedade privada ${ }^{2}$. É, em última instância, na construção de contrapontos a essa associação que este artigo situa a leitura dos argumentos sobre a liberdade, escritos pelo jovem Marx. Com esse propósito, analisa-se parte dos argumentos do jovem Marx, obras elaboradas no período de 1841 a 1844 , que convergem para a crítica da associação entre a liberdade e o direito de propriedade. Procedeu-se, para o cumprimento desses objetivos, a uma revisão bibliográfica, orientada pela análise estrutural das obras mencionadas, com o auxílio de autores, para os quais, em tese, elas inauguram uma nova ontologia: a ontologia social. Essas pesquisas foram realizadas durante as atividades junto ao Programa de Pós-Graduação em Ciências Sociais da Unesp - Campus Marília, em nível de pós-doutorado, durante o primeiro semestre do ano de 2010, sob a supervisão do Prof. Dr. Antônio Carlos Mazzeo. Esses estudos deram origem a uma nova pesquisa sobre essa temática ${ }^{3}$, que se encontra em fase inicial, realizada com equipe de discentes na Universidade Estadual de Londrina.

\section{A compreensão da liberdade para o jovem Marx: elementos para a crítica de sua associação à propriedade privada}

Duas perspectivas éticas destacam-se entre as que se erigem, ainda na antiguidade (século 3 a.C.), no contexto da desagregação da cidade Grega: o estoicismo e o epicurismo ${ }^{4}$. Destacam-se porque são perspectivas que, já no contexto da Grécia antiga, abandonam a sustentação da intrínseca relação entre ética e política que caracterizava as grandes sistematizações da época, nos limites de uma sociedade que, por um curto período, orientou-se politicamente pela democracia. E não se trata, obviamen- te, de um movimento filosófico à margem de seu tempo. Ao contrário, sobre a perda da hegemonia política e sob a dominação estrangeira ${ }^{5}$, a reflexão sobre o que orienta as condutas humanas não se circunscreve mais aos limites de uma cidade.

Os grandes representantes da Paideia Grega Platão e Aristóteles ${ }^{6}$ - fundaram, embora por vias contrárias, a reflexão da ética a partir de sua associação com a política. $\mathrm{Na}$ formulação platônica, esse fato pode ser constatado na associação das condutas individuais à formação do caráter virtuoso, que é estritamente vinculada à possibilidade de alcançar o Bem, ideal da cidade justa ${ }^{7} \mathrm{ou}$, ainda, na formulação aristotélica com relação à construção da mediania e do ideal da eudaimonia (bem comum) ${ }^{8}$, perspectiva que se põe como imperativa ao homem que, na condição de animal político, necessariamente se associa com os outros homens para viver bem. Sobre esses pressupostos, as escolhas humanas deveriam associar-se a finalidades que ultrapassassem interesses individuais para convergir, respectivamente, na idealização de uma cidade justa (Platão) ou na cidade fundada no bem comum (Aristóteles). A liberdade era, então, associada à construção da virtude, da justiça e da vida boa; ultrapassava-se, na representação filosófica, a vinculação da liberdade a interesses individuais, e era na perspectiva da preservação do coletivo, e não dos espaços individuais, que se erigia a reflexão ética.

Essa demarcação do contexto grego é necessária para introduzir a análise da centralidade da liberdade na discussão da ética a partir do século 18 , período em que a moral iluminista volta-se para a valorização da racionalidade e é conjugada com a exacerbação do trabalho livre, o que figura como uma das mediações para a defesa do ideário liberal que associa a liberdade à propriedade privada e aos comportamentos individuais. Contudo, já entre os gregos, nas perspectivas do epicurismo e estoicismo, evidenciam-se os primeiros contornos da frágil associação da ética à construção do bem comum e já aparecem os contornos do universalismo ético.

Para Marx (1979, p. 17): "a morte dos heróis assemelha-se ao pôr do sol e não ao rebentar de uma rã que tenha inchado". Sem os contornos das cidades gregas e do modo de produção a partir do qual elas se organizavam, as insígnias dos grandes filósofos - "Em cada um de nós estão presentes as mesmas partes e caracteres que na cidade" (PLATÃO, 1986, p. 435) e "Não é apenas para viver juntos, mas sim para bem viver juntos que se fez o Estado" (ARISTÓTELES, 1991, p. 45) - dão lugar, ainda no século 3 a.C., às reflexões que vinculam as condutas humanas à organização do cosmos e ao movimento da matéria. Da organização da cidade volta-se, então, no período helenístico, para uma análise da física que se torna, concomitantemente, substrato material para a suposi- 
ção de que as ações humanas devem se orientar para a autorrealização, que tem como exercício constante a construção da ataraxia na solidão. Compreender a ordem na natureza torna-se fundamental para alcançar essa ataraxia que, ao contrário de uma reclusão individual, representa a síntese da harmonia do homem com a natureza da qual ele é parte; e que significa, portanto, viver com serenidade e em interação com o natural (autorrealização). Nasce, então, uma perspectiva universalista que, entre os estoicos e os epicuristas $^{9}$, dois de seus maiores expoentes, tem traduções diversas. E é na análise de um epicurista que se inscreve uma primeira produção teórica de Marx, a tese de doutorado iniciada em 1839 e apresentada sob o título Diferença entre as filosofias da natureza em Demócrito e Epicuro (1841). E é o próprio filósofo (1979, p. 18) que explica o seu propósito: "Só insisto neste aspecto para recordar a importância histórica desses sistemas: mas não tratamos aqui de sua importância para a civilização em geral: o que nos interessa é sua conexão com a filosofia grega anterior."

Nessa tese de doutorado, estão presentes aspectos sobre a importância da compreensão da liberdade em uma perspectiva materialista, o que pode ser identificado na afirmação de $\operatorname{Marx}$ (1979, p. 23-24): "Demócrito reduz o mundo sensível à aparência subjetiva, Epicuro faz dele um fenômeno objetivo. E Epicuro [...] não converte as qualidades sensíveis em simples objetos da opinião". Ao contrário, continua Marx, no desenvolvimento de seu argumento, ele: "[...] encontra a satisfação e a felicidade na filosofia". Será necessário - diz - "que sirvas à filosofia para que obtenhas a verdadeira liberdade. Quem se lhe dedica e entrega não precisa esperar; é imediatamente emancipado. Pois servir à filosofia significa liberdade."

Para Lukács (2007, p. 126), nesses estudos de Marx são apresentadas críticas que se dirigem a aspectos importantes da concepção hegeliana de história e demarcam a diferença da interpretação construída por Hegel sobre a filosofia nesse período helenístico. Hegel, nessa interpretação de Lukács, afirmava a importância secundária das filosofias helenística e romana, do estoicismo e epicurismo, frente ao ceticismo. Marx, ao contrário, interpreta a contribuição filosófica de Epicuro como superior aos céticos, sobretudo, pelo seu propósito de libertar o "homem do temor dos Deuses": "Não atribuas a ela [a divindade] nada que seja incompatível com a sua imortalidade, nem inadequado à bem-aventurança; pensa a respeito dela tudo o que for capaz de conservar-lhe a felicidade e imortalidade" (EPICURO, 2002, p. 23).

O que Marx pretendia, ao assinalar contrapontos entre as teorias atomistas de Demócrito e Epicuro ${ }^{10}$, era, entre outros aspectos, investigar possíveis traços da dialética na doutrina deste último. E, nesse propósito, mostra que, enquanto Demócrito, restrito ao conhecimento da necessidade mecânica, nega o acaso, a filo- sofia epicurista já apresenta "elementos iniciais de uma concepção dialética do acaso, que abria ao homem o caminho para a liberdade" (LUKÁCS, 2007, p. 128).

Ao empirismo rígido de Demócrito, levanta-se o contraponto do ideal da ataraxia, ponto culminante na trajetória da relação entre o homem e a natureza, erigida no ideário epicurista. Para Lukács (2007), ao explicitar tal contraponto, Marx interpreta que estão postos por Epicuro argumentos que concorrem para afirmação da relação entre o conhecimento da natureza e a libertação do homem:

\begin{abstract}
Na medida em que reconhecemos a natureza como algo racional, desaparece a nossa dependência em face dela. Ela não mais atemoriza nossa consciência [...]. Somente dando livre curso à natureza é que a razão consciente, considerando a natureza como razão em si mesma, dela se apropria inteiramente (MARX apud LUKÁCS, 2007, p. 129).
\end{abstract}

Marx, como afirma Lukács (2007), estabelece uma interlocução crítica com o conceito de "liberdade universal" formulada no sistema hegeliano e, ainda que nesse momento não tenha ultrapassado o idealismo desse sistema, faz demarcações que caracterizam o seu percurso inicial em direção ao materialismo. Dentre estas, Lukács salienta a identificação de elementos dialéticos na perspectiva materialista metafísica de Epicuro. Na verdade, Marx estabelece contrapontos com tal perspectiva e neles formula uma concepção universal da história sobre uma nova base, a material. Está, portanto, construindo uma interlocução crítica com a concepção idealista de Hegel sobre a universalidade da história.

Dois anos após a conclusão dessa tese de doutorado (1841), num rigoroso estudo sobre a "filosofia do direito de Hegel”, Marx condiciona a revolução radical, a que não "deixa em pé os pilares do edifício", apenas ao momento em que "uma seção da sociedade civil emancipa-se e alcança o domínio universal: uma determinada classe empreende, a partir da sua situação particular, uma emancipação geral da situação". E considera que o desempenho deste papel dá-se apenas quando uma classe for capaz de:

[...] despertar em si e nas massas, um momento de entusiasmo em que se associe e misture com a sociedade em liberdade, se identifique com ela e seja sentida e reconhecida como a representante geral da referida sociedade [...]. Só em nome dos interesses gerais da sociedade é que uma classe particular pode reivindicar a supremacia geral. Para alcançar esta posição libertadora e a direção política de todas as esferas da sociedade, não bastama energia e a consciência revolucionárias. Para que a revolução de um povo e a emancipação de uma classe particular da sociedade civil coincidam, para que um 
estamento seja reconhecido como o estamento de toda sociedade, um estamento particular tem de ser o estamento de repúdio geral, a incorporação dos limites gerais. Uma esfera particular terá de olhar-se como crime notório de toda a sociedade, a fim de que a libertação de semelhante esfera surja como autolibertação geral (MARX, 2006, p. 154).

Marx se refere, nesse contexto, ao proletariado como uma classe capaz de protagonizar o que, naquele momento, chama de interesses gerais. Embora ainda não identifique o trabalho como constitutivo do ser social, já associa a universalidade e a liberdade à superação dos limites inerentes aos interesses individuais. Nesse sentido, ressalta a importância do protagonismo de uma classe:

[...] que [possui] caráter universal porque os seus sofrimentos são universais e que não exige uma reparação particular porque o mal que lhe é feito não é um mal particular, mas o mal em geral, que já não posso exigir um título de histórico, mas apenas o título humano; de uma esfera que não se oponha a consequências particulares, mas que se oponha totalmente aos pressupostos do sistema político alemão; por fim, de uma esfera que não pode emancipar-se a si mesma nem se emancipar de todas as outras esferas da sociedade sem emancipá-las todas - o que é, em suma, a perda total da humanidade, portanto, só pode redimir-se a si mesma por uma redenção total do homem (MARX, 2006, p. 156).

Marx está, portanto, na gênese da construção de uma nova tradução da liberdade. Sem se afastar da base materialista, mas analisando-a a partir de sua historicidade, para além da crítica de seus interlocutores mais próximos, os jovens hegelianos que entendiam ter encontrado na crítica da religião o contraponto para a redenção humana, volta-se à análise da liberdade a partir do Estado e da sociedade. É a partir dessa base real que se criam as situações ilusórias, e dentre essas a religião, que devem ser superadas para a inversão do movimento humano. Instaura-se a possibilidade de um movimento no âmbito do qual o homem possa deixar de "guiar-se por um sol ilusório e reconhecer-se como ponto de partida". Trata-se de um novo momento histórico no qual a filosofia deve "desmascarar a autoalienação humana nas suas formas não sagradas, agora que ela foi desmascarada na sua forma sagrada"; um momento em que se deve passar "a crítica da religião para a crítica do direito, e a crítica da teologia em crítica da política" (MARX, 2006, p. 146-147).

Na perspectiva dessa inversão, em outro percurso, em A questão judaica, de 1843, Marx (1969) examina a concepção universal sobre a qual se constrói a idealização da igualdade formal do Estado de direito, com o propósito de "investigar a relação entre a emancipação política e a emancipação humana" (MARX, 1969, p. 19). E, no âmbito dessa crítica, associa a vinculação entre liberdade e propriedade à defesa de interesses que, de fato, são contrários à universalidade, porque se inscrevem na dicotomia entre igualdade formal (política) e desigualdade real (que nasce de uma sociedade que se organiza a partir de interesses privados).

$\mathrm{O}$ Estado e as leis que dele derivam figuram como construto abstrato na defesa de um interesse comum idealizado; como um "mediador entre o homem e sua liberdade" e, na realização desse papel, "anula, a seu modo, as diferenças de nascimento, de status social, de cultura e de ocupação do homem como diferenças não políticas" (MARX, 1969, p. 24-25). Contudo:

[...] deixa que a propriedade privada, a cultura e a ocupação atuem a seu modo, isto é, como propriedade privada, como cultura e como ocupação, e façam valer sua natureza especial. Longe de acabar com estas diferenças, o Estado só existe sobre tais premissas, só se sente Estado político e só faz valer sua generalidade em contraposição a estes elementos seus (MARX, 1969, p. 25).

Para Marx (1969), atribui-se ao Estado, à semelhança do que as religiões atribuem a Deus, a defesa de uma igualdade irrealizável. Os interesses individuais, egoístas, permanecem intocáveis. Além disso, inscreve-se, com o Estado, a sacralização de uma vida dupla: o homem vive (tanto no plano do pensamento como no da realidade), concomitantemente, na esfera política e na sociedade civil. O Estado político figura-se, então, com uma "sofística" que lhe é inerente e, nessa concepção, o cidadão nasce a partir da abstração da sociedade burguesa.Ele estabelece, então, em relação à sociedade civil, uma mediação tão idealizada quanto a que põe na esfera da religião e não suprime, mas, ao contrário, contempla o individualismo burguês. Para indicar esse individualismo, Marx (1969) adverte, entre outros aspectos, para a forma pela qual a liberdade se inscreve na defesa da "Declaração dos Direitos Humanos e dos Cidadãos": esta aparece atrelada à esfera de direitos e se restringe ao "direito de fazer e empreender tudo aquilo que não prejudique os outros"; numa imposição de limites legais e não de possibilidades de convivência entre os homens. Posta nesses termos, a liberdade torna-se uma "mônada isolada, dobrada sobre si mesma" e indica uma perspectiva de direito que "não se baseia na união do homem com o homem, mas pelo contrário, na separação do homem em relação a seu semelhante. A liberdade é o direito a esta dissociação, o direito do indivíduo delimitado, limitado a si mesmo" (MARX, 1969, p. 42). 
Liberdade torna-se, então, o direito à propriedade privada, e é associada ao direito de "desfrutar" o patrimônio que lhe é próprio; o que evidencia sua representação nos limites da sociedade burguesa. A liberdade é interpretada na perspectiva de um suposto estado natural em que se prima pela "necessidade e [pelo] interesse particular"; pela conservação de propriedades e de "individualidades egoístas" (MARX, 1969, p. 45).

Esse percurso teórico de Marx, que assentava-se, sobretudo, à crítica ao idealismo hegeliano e à interpretação, também idealista, dos jovens hegelianos, amplia-se com o debate que estabelece com os economistas políticos, sobretudo Adam Smith e Ricardo, nos Manuscritos econômico-filosóficos de 1844. Um novo marco delineia-se na análise da liberdade. Marx identifica a liberdade como um atributo constitutivo do ser social e, como tal, inerente ao gênero humano e não aos indivíduos sociais atomizados em esferas que o limitam ao horizonte da propriedade privada que inverte o sentido do que constitui a sociabilidade humana: o trabalho. Estabelece as bases de uma nova ontologia que demarca o rompimento com a metafísica clássica e que traduz a necessária relação entre a liberdade e a construção de uma nova sociabilidade, possível apenas com a superação da propriedade privada.

Marx (1994) mostra que os economistas políticos enaltecem o valor do trabalho para construção da riqueza social, entretanto, alheios à historicidade humana e ao caráter ontológico do trabalho, não consideram o processo de desumanização sofrido pelo trabalhador no modo de produção capitalista, no qual o trabalho torna-se mercadoria e é submetido ao valor de troca em detrimento de suas peculiaridades humanossociais. Ele mostra, portanto, que a interpretação do trabalho como mercadoria inverte o sentido de uma força viva: o trabalho humano. No âmbito dessa análise, situa a ausência da liberdade posta na lógica do modo de produção capitalista que retira dos sujeitos sociais a sua própria condição de sujeitos para transformá-los em objetos e em mercadorias. Mostra que sob as leis da oferta e da procura e submetidos aos efeitos nocivos das oscilações de preço do mercado, como a miséria e o encurtamento da vida, as aspirações humanas são substituídas pelo consumo e pela produção, os quais se fundam como pilares de uma liberdade ilusória e que se afirmam como conquistas individuais associadas à propriedade.

Argumentos reiterativos de Marx, ao longo dessa análise crítica às teses defendidas pela economia política com relação ao produto do trabalho, ao valor da natureza, à divisão do trabalho e à relação do capitalista com a sociedade, revelam que, para essa ciência, o trabalho gera riquezas e poder de compra. Mas, ao contrário, a realidade evidencia que o produto do trabalho é acessível àquele que o produziu apenas para garantir sua existência como operário; ou seja, o tra- balho "não compra tudo", não gera poder de compra para o operário, mas o obriga a "vender-se a si próprio e à própria humanidade". Evidenciam, também, que, se a divisão do trabalho eleva a força produtiva do trabalho e o desenvolvimento da sociedade, "empobrece o operário até à condição de máquina" (MARX, 1994, p. 18-19) que precisa de manutenção para o seu funcionamento. Reduzido a tal condição, o trabalhador vive para a garantia de sua sobrevivência física, seu trabalho figura como "atividade de ganha-pão", erwerbsthätigkeit, e ele é reconhecido como "animal de trabalho" reduzido às necessidades corporais. $\mathrm{Na}$ verdade, adverte Marx (1994, p. 22):

\section{Um povo, para se formar de um modo espiritual- mente mais livre, não pode permanecer na escra- vatura das suas necessidades corpóreas, não pode continuar a ser o servo do corpo. Antes de mais, tem de lhe restar 'tempo' para 'poder' também criar espiritualmente e fruir espiritualmente.}

Ao contrário dessa possibilidade criativa, a partir de uma análise que tem como ponto de partida os fatos econômicos, reais, Marx ressalta o trabalho alienado. Considera que a economia política não o elucida, porque parte da propriedade privada, mas não a esclarece. Inverte-se nessa crítica de Marx o sentido político posto no ideário liberal, que parte da associação entre liberdade e trabalho como condição de ampliação da propriedade, uma vez que o trabalho amplia a propriedade do próprio corpo humano (mãos, pés) nos objetos que advêm do seu resultado ${ }^{11}$. Ao contrário, na crítica marxiana, o trabalhador não pode reconhecer-se no produto do seu trabalho e, além disso, o "objeto que o trabalho produz, o seu produto, enfrenta-o como um ser estranho, como um 'poder independente' do produtor'. O produto do trabalho torna-se "trabalho que se fixou num objeto, se coisificou" (MARX, 1994, p. 62). O trabalhador põe sua vida no objeto, porém, ela não lhe pertence; porque é transferida para o objeto e

\section{[...] quanto maior é esta atividade, mais privado de objeto fica o operário [...]. O produto do seu tra- balho é. Ele não é. O desapossamento do operário no seu produto tem o significado, não só de seu trabalho se tornar um objeto, uma existência 'ex- terior', mas também de que ele existe 'fora dele', independente e estranho a ele, de que a vida, que ele emprestou ao objeto, o enfrenta de modo es- tranho e hostil (MARX, 1994, p. 63).}

Se o produto do trabalho é desapossamento, a própria atividade produtiva também o é. Não há, portanto, qualquer possibilidade de relacionar trabalho com liberdade no modo de produção fundado como propriedade privada. Ao contrário, sob tal lógica, o trabalha- 
dor "só se sente livremente ativo nas suas funções animais - comer, beber e procriar, quando muito ainda habitação, adorno etc. - e já só como animal nas suas funções humanas" (MARX, 1994, p. 65).

A universalidade, nessa crítica de Marx, está associada ao domínio da natureza inorgânica em que o homem vive. Ele considera que, ao ter esse domínio retirado por um modo de produção que impõe atividades mecânicas e associadas a ideais criados pelo consumo e produção, os homens só podem se reconhecer como indivíduos atomizados, ou seja, não podem se reconhecer como pertencentes ao gênero humano; como seres que, a partir da atividade na natureza, tornam objeto seu o seu gênero; como seres que, ao objetivarem-se na natureza, podem se comportar para consigo como gênero vivo, o que é condição de liberdade.

Marx refere-se, aqui, ao trabalho como construção do ser social que tem como base primária a relação intrínseca entre o homem e a natureza. Considera que se o homem vive na natureza, ela é o seu corpo, mas se o trabalho, em sua realização, é alienado, ele também aliena ao homem:

1) a natureza, 2) ele próprio, a sua função ativa, sua atividade vital, assim ele aliena ao homem o gênero, torna-lhe a vida genérica meio da vida individual. Primeiro, aliena a vida genérica e a vida individual e, segundo, torna a última na sua abstração objetivo da primeira, igualmente na sua forma abstrata e alienada. Pois, em primeiro lugar, o trabalho, a atividade vital, a própria vida produtiva, aparece ao homem apenas como um meio para a satisfação da necessidade de manutenção da existência física. Mas a vida produtiva é a vida genérica. É a vida que gera vida. No modo de atividade vital reside todo o caráter de uma species, o seu caráter genérico e a atividade livre e consciente [...]. A própria vida aparece apenas como meio de vida (MARX, 1994, p. 67).

Transformada em meio de garantir a existência física, a vida do homem torna-se carregada de determinações alheias à sua escolha e ele se confunde com elas e se distancia da possibilidade de escolhas autônomas. Ou seja, ele só é um ser consciente; ou, ainda, a sua própria vida é para ele objeto, precisamente porque ele é um ser genérico: "O gerar prático de um mundo objetivo, a elaboração da natureza inorgânica, é a prova do homem como um ser genérico consciente, isto é, um ser que se comporta para com o gênero como sua própria essência ou para consigo como ser genérico" (MARX, 1994, p. 68).

Propriedade privada é "a consequência necessária do trabalho desapossado, da relação exterior do operário com a natureza e consigo próprio". Ela "resulta do trabalho desapossado, da vida alienada, do homem alienado"; ela é o "meio através do qual o trabalho se desapossa, a realização deste desapossamento" (MARX, 1994, p. 71). Ela não é, portanto, resultado da relação entre trabalho e liberdade, como propõe o ideário liberal, mas, ao contrário, é a negação da liberdade. Assim, as relações entre os homens, movidas por uma sociabilidade que se erige na defesa dessa propriedade, não são orientadas por um horizonte ético. Evidencia-se que o ideário liberal, ao identificar a propriedade privada como constitutiva de um suposto estado de natureza, torna-se premissa para interpretação das categorias econômicas como leis imutáveis e para tratar essas leis de forma empírica, sem compreendê-las em sua essência.

Liberdade, na crítica do jovem Marx, está associada à possibilidade do reconhecimento da própria humanidade que nasce da relação do homem com a natureza, estabelecida a partir de necessidades, de fato, humanas. Há que postular, portanto, pela "abolição positiva da propriedade privada", ou seja, a consolidação do comunismo. Tal perspectiva é a condição de liberdade porque possibilita o retorno do homem a si mesmo como um ser "social", isto é, realmente humano, "um regresso completo e consciente e advindo dentro de toda a riqueza do desenvolvimento até agora" (MARX, 1994, p. 92).

O comunismo tem, nessa análise, sua base empírica no próprio movimento da propriedade privada. A defesa de sua possibilidade parte da premissa de que as derivações do modo de produção capitalista, superestruturas que o sustentam, podem perder sua fixidez; o que torna possível o retorno do homem à sua própria natureza:

Religião, família, Estado, direito, moral, ciência etc.; são apenas modos particulares da produção e caem sob sua lei universal. A supressão positiva da propriedade privada como apropriação da vida humana é, por isso, a supressão de toda a alienação, portanto o regresso do homem [...] à sua existência humana, isto é, social. A alienação religiosa como tal processa-se apenas no domínio da consciência, do interior humano, mas a alienação econômica é a da vida real - por isso sua supressão abrange ambos os lados (MARX, 1994, p. 93).

Sem a propriedade privada, o homem pode se reconhecer como ser social, ou seja, "apropriarse da própria existência". Nos termos de Marx: "O que eu faço de mim, o faço para a sociedade e com a consciência de mim enquanto ser social". A possibilidade da escolha, a possibilidade da liberdade, não está, portanto, associada a interesses individuais, mas à "consciência da universalidade" que é, apenas, "uma expressão 'teórica' daquela cuja forma 'viva' é a comunidade real" (MARX, 1978, p. 10). 
A sociedade não é uma construção formal que nasce da necessidade de os homens estabelecerem uma convivência não conflitante, mas, ao contrário, é dimensão da própria existência dos indivíduos. A própria exteriorização dos indivíduos sociais é "uma exteriorização e confirmação da vida social". A liberdade não é, portanto, associada ao direito de propriedade, mas, ao contrário, é possibilidade de reconhecimento da própria sociabilidade. Essa "superação positiva da propriedade privada", ou seja, a "apropriação sensível pelo homem e para o homem da essência e da vida humana" esvazia de sentido a orientação das escolhas às posses, ao ter. Torna-se, possível associá-las, então, ao ser. Foi necessário, entretanto, diz Marx, reduzir o homem à absoluta pobreza, para que esse processo "pudesse dar à luz a sua riqueza interior partindo de si" (MARX, 1994, p. 97). A liberdade pode, então, traduzir-se como conquista da autonomia, como possibilidade de criação da própria vida, sem ter "um fundamento fora de si"; sem que ela não seja a apropriação de outro, estranho. E essa é a perspectiva do socialismo:

\begin{abstract}
Toda a chamada história do mundo não é senão a geração do homem, pelo trabalho humano, senão o devir da natureza para o homem, assim ele tem, portanto, a prova irrefutável, intuível, do seu nascimento através de si próprio, do seu processo de surgimento [...]. O socialismo é a autoconsciência positiva do homem, já não mediada pela supressão da religião, tal como a vida real é realidade positiva do homem já não mediada pela supressão da propriedade privada, o comunismo. O comunismo é a posição como negação da negação, por isso o momento real, necessário para o próximo desenvolvimento histórico, da emancipação e recuperação humanas (MARX, 1994, p. 104).
\end{abstract}

Para que se possa ultrapassar esse "dever ser" posto pela economia política, faz-se necessário superar as condições materiais sobre as quais ele se estrutura, o que implica a superação da conformação dos limites da liberdade aos limites desse próprio dever ser. Não é na conformação ao dever ser posto pelo Estado que está a possibilidade da liberdade. Não é na defesa de direitos individuais, inalienáveis, que está a garantia da liberdade; mas, ao contrário, ela só é possível com a superação de um modo de produção que retira a possibilidade de escolhas, de fato, humanas, porque movidas pela lógica do consumo.

\section{Considerações finais}

O retorno a esses percursos iniciais da crítica de Marx permite ratificar que a interpretação da liberdade, central para a reflexão ética, impõe uma necessária relação a uma matriz política. Não se trata de idealizar a relação entre elas nos moldes das reflexões de Platão e Aristóteles; mas se trata, sim, de refletir de forma crítica sobre a necessária superação da dicotomia entre as ações dos homens e a moralidade que se impõe sob o ideário liberal e sob a moldura de um Estado de direito. Liberdade, na perspectiva da crítica marxiana, é constitutiva da práxis humana e se refere à relação entre teleologia e causalidade. Nos termos de Heller (1972), substancialmente, tais constitutivos não são antinômicos, mas encerram uma relação dialética; causalidades são, também, construídas a partir de ações humanas e é possível que as escolhas conscientes possam movimentá-las. Sem esse esforço, tais causalidades aparecem como fatos dados e perpetuase a defesa de uma sociabilidade fundada na desigualdade, em que não há possibilidade de escolhas autônomas. Ratifica-se, assim, a necessária superação da defesa da liberdade individual associada aos limites postos por uma universalidade abstrata fundada em máximas morais e em formulações jurídicas.

Interpretar a liberdade como garantia de direitos, sem remissão à crítica marxiana, é afastar-se do sentido a ela atribuído no primeiro princípio do código de ética profissional dos assistentes sociais e ao projeto ético-político do Serviço Social. De forma similar, sustentar a necessária defesa de direitos, sem a análise crítica da fragilidade do ideário de universalidade e igualdade que os sustentam, pode limitá-la aos contornos possíveis dos limites da sociabilidade burguesa. É nessa direção que se pretende reiterar, com as reflexões aqui apresentadas, que a defesa da liberdade está associada a uma perspectiva política que tem na crítica à propriedade privada um de seus pilares fundamentais. Reitera-se, também, que a associação entre liberdade e propriedade privada é problemática, entre outros aspectos, porque tal associação se põe como um dos fundamentos para o entendimento da ética como preservação de um suposto espaço coletivo a partir da delimitação de possibilida- 
des individuais, sancionadas legalmente, e que corroboram para o distanciamento do reconhecimento do próprio gênero humano; um entendimento avesso, de fato, à ética. Não há como pensar no horizonte da ética sem desvencilhar-se das ciladas postas pelo ideário liberal, que interpreta a liberdade como subjugada a limites para escolhas individuais. Não há, portanto, como dissociar a análise ética do debate político que ela impõe; caso contrário, distancia-se do projeto ético-político defendido pela categoria profissional dos assistentes sociais.

\section{Referências}

ARISTÓTELES. A política. São Paulo: Martins Fontes, 1991.

Ética a Nicômaco. São Paulo: Abril, 1978. (Coleção Os Pensadores).

BARROCO, M. L. Os fundamentos sócio-históricos da ética. In: CAPACITAÇÃO em Serviço Social e política social: reprodução, trabalho e Serviço Social. Brasília: CFESS/CEAD, 1999. (Módulo II).

BORHEIM, G. O sujeito e a norma. In: NOVAES, A. (Ed.). Ética. São Paulo: Companhia das Letras, 1994.

BRUN, J. O estoicismo. Lisboa: Edições 70, 1986. (Biblioteca Básica de Filosofia).

O epicurismo. Lisboa: Edições 70, 1987. (Biblioteca Básica de Filosofia).

CFESS-Conselho Federal de Serviço Social. Código de Ética profissional do Assistente Social. Brasília: CFESS, 1993.

EPICURO. Carta sobre a felicidade - A Meneceu. São Paulo: Unesp, 2002.

HELLER, A. O cotidiano e a história. Tradução de Carlos Nelson Coutinho e Leandro Konder. Rio de Janeiro: Paz e Terra, 1972.

JAEGER, V. Paideia: a formação do homem grego. São Paulo: Martins Fontes, 1989.

LOCKE, J. Segundo tratado sobre o governo. São Paulo: Abril, 1978. (Coleção Os Pensadores).

LUKÁCS, G. O jovem Marx e outros escritos de filosofia. Rio de Janeiro: Editora UFRJ, 2007.

MARX. K. A questão judaica. Rio de Janeiro: Laemmert, 1969.
. Para a crítica da economia política. São Paulo: Abril, 1978. (Coleção Os Pensadores).

. Da diferença entre as filosofias da natureza em Demócrito e Epicuro. São Paulo: Editora Global, 1979.

. Manuscritos econômico-filosóficos de 1844. Lisboa: Edições Avante, 1994.

Crítica da filosofia do direito de Hegel. São Paulo: Boitempo, 2006.

OLIVEIRA. R. A. Considerações acerca da liberdade e da ética na tese "A diferença entre as filosofias da natureza em Demócrito e Epicuro" de Karl Marx. Polymatheia Revista de Filosofia, Fortaleza, v. 4, n. 6, p. 251-265, 2008.

PAULO NETTO, J. A construção do projeto éticopolítico profissional frente à crise contemporânea. In: CAPACITAÇÃO em Serviço Social e política social: reprodução, trabalho e Serviço Social. Brasília: CFESS/ CEAD, 1999. (Módulo I).

PLATÃO. A república. Lisboa: Calouste Gulbenkian, 1986.

\section{Notas}

1 Vários são os autores e as produções teóricas que fazem essa referência, como, por exemplo: Barroco (1999) e Paulo Netto (1999).

2 Borheim (1994), para discutir as relações entre o sujeito e a norma no século 18, apresenta, de forma sumária, uma série de características que decorrem do modo de produção capitalista e que se delineiam ao longo deste século. O autor refere-se ao individualismo burguês como algo que oxigena todo o edifício erigido sobre esse modo de produção e situa, dentre outras características, as que ora são apresentadas.

3 Título da pesquisa: A categoria liberdade: sua interpretação na crítica marxiana e sua apreensão como princípio ético-político na categoria profissional dos assistentes sociais.

4 Uma análise introdutória sobre o pensamento filosófico que recebe essas denominações pode ser encontrada nas obras de Brun (1986, 1987).

5 Referência ao período de dominação macedônica, sob as conquistas de Alexandre, o Grande, em que se instaura a cultura helenística.

6 Vários são os expoentes da Paideia Grega, como é possível constatar, entre outras, na obra de Jaeger (1989). 
Fundamental, por exemplo, é o marco inaugural da reflexão ética, com Sócrates. Alimitação a esses dois expoentes devese à associação que em ambos está desenvolvida de forma contundente com relação à vinculação da ética à política.

7 Platão idealiza uma "República" perfeita, no diálogo que recebe esse nome. Toda a investigação, que constrói com seus interlocutores nesse debate, parte da análise da Justiça como algo que se faz tanto no plano externo (político) quanto no plano interno (individual). Preocupa-se em entender como produzir uma alma bem ordenada (a menor forma)eépossível garantir uma cidade (a maior forma) bem ordenada e objetiva, ou seja, é a partir de cada caráter virtuoso (de cada particular) que a Cidade pode se tornar bem ordenada (PLATÃO, 1986).

8 Toma-se como referência para análise destes conceitos, nesta pesquisa, as seguintes obras de Aristóteles: Livro I da Ética a Nicômaco e A política.

9 Para os primeiros, ela deve conduzir ao ideal da apatheia, do que deriva a compreensão da liberdade como circunscrita ao conhecimento que cada sujeito deve ter em relação a seu lugar na natureza, na ordem universal e cabe, portanto, ao homem cumprir sua necessária interação com essa ordem. Para os segundos, ao contrário, essa universalidade deve conduzir à preponderância das escolhas individuais sobre a certeza de que a ordem natural, universal, não se tece sobre o império da ação de deuses estranhos a essas escolhas; liberdade é, então, construção diária, nos limites do tempo da existência, de escolhas desvencilhadas de excessos estranhos aos prazeres humanos e naturais.

10 Marx, ao tratar da relação entre as teses de Demócrito e Epicuro, considera que as discussões "suscitadas pelo atomismo constituíram-se em temas clássicos da tradição filosófica" (OLIVEIRA, 2008, p. 252); mas a importância histórica atribuída por Marx ao tratamento dessa temática deve-se, também, ao ambiente filosófico alemão no qual ele estava inserido. Discutia-se, no final do século 18, acerca dos "princípios fundamentais da realidade e do conhecimento" e no "movimento jovem hegeliano, do qual Marx fazia parte, pesquisava-se sobre a "possibilidade de explicar o real a partir de um princípio universal"' (OLIVEIRA, 2008, p. 254). Marx buscou, então, na filosofia atomista grega, esse princípio, a partir de uma base material e não pela perspectiva abstrato-especulativa do idealismo. Parte de um contraponto a pensadores clássicos que na tradição filosófica se posicionaram criticamente em relação à apropriação que Epicuro faz da filosofia de Demócrito; distancia-se desse contraponto ao apresentar, entre outros aspectos, a diferenciação genérica de aspectos fundamentais que sustentam os sistemas físicos propostos por esses filósofos.

11 Sobre esse tema, ver Locke (1978), Da propriedade, capítulo V, p. 43-54.

\section{Olegna de Souza Guedes}

olegna@uel.br

Doutorado em Serviço Social pela Pontifícia Univer-

sidade Católica de São Paulo (PUC-SP)

Docente na Graduação e Pós-Graduação, Departamento de Serviço Social da Universidade Estadual de Londrina (UEL)

UEL - Departamento de Serviço Social Campus Universitário

Rodovia Celso Garcia Cid, PR 445, Km 380

Cx. Postal 6001

Londrina - Paraná

CEP: 86051-980 